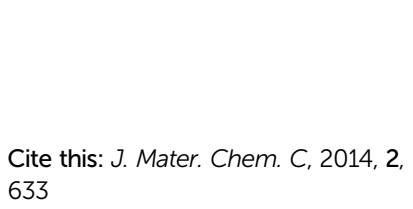

633

Received 25th September 2013 Accepted 24th October 2013

DOI: $10.1039 / c 3 t c 31888 \mathrm{e}$

www.rsc.org/MaterialsC

\title{
Controllable preparation of nanocomposites through convenient structural modification of cobalt contained organometallic precursors: nanotubes and nanospheres with high selectivity, and their magnetic properties $\uparrow$
}

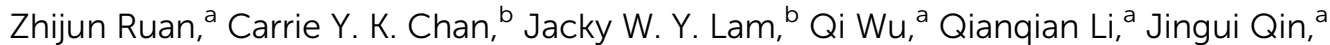 \\ Ben Zhong Tang ${ }^{\mathrm{b}}$ and Zhen $\mathrm{Li}^{\star a}$
}

\begin{abstract}
For the first time, POSS moieties were introduced to organometallic precursors, PM1 and PM2, for solidstate pyrolysis, in which PM1 contained one $\left[\mathrm{CO}_{2}(\mathrm{CO})_{6}\right]$ unit, while PM2 contained two. For comparison, their analogues, M1 and M2 without POSS groups, were also prepared. By regulating the number of $\left[\mathrm{CO}_{2}(\mathrm{CO})_{6}\right]$ moieties and introducing the POSS group, the morphology and size of the obtained nanocomposites could be well controlled: uniform nanotubes could be obtained from M2 and PM2, while uniform nanospheres from M1 and PM1. Also, the size of the obtained nanocomposites from PM1 (PM2) is much smaller than that of M1 (M2). The obtained carbon/metal nanocomposites demonstrated good magnetic properties, with Ms values up to $33.4 \mathrm{emu}^{-1}$, making them promising candidates for practical applications.
\end{abstract}

\section{Introduction}

Carbon-based materials, especially hybrids of metal nanoparticles with nanostructures, have attracted growing interest, due to their novel structure and unique electronic, photonic, thermal, magnetic, and mechanical properties. Different approaches have been successfully explored for the preparation of various functional carbon-based materials, in which the transition metal catalyzed solid-state pyrolysis of well defined, carbon-rich precursors, generally organic molecules and polymers, was a promising one for large scale production, ${ }^{\mathbf{1}}$ and demonstrated relatively good control of the defined carbon materials. ${ }^{2}$ By choosing some special metal, the yielded carbonbased materials could exhibit magnetic properties, and be utilized for a wide range of applications, such as bio-detection, magnetic carriers for drug targeting, magnetic resonance imaging and information storage. ${ }^{3}$ More importantly, the metal nanoparticles formed in the pyrolysis process could be wrapped by the carbon atoms, to avoid their aggregation and oxidation

${ }^{a}$ Department of Chemistry, Hubei Key Lab on Organic and Polymeric Opto-Electronic Materials, Wuhan University, Wuhan 430072, China. E-mail: lizhen@whu.edu.cn; lichemlab@163.com; Fax: +86-27-68755363; Tel: +86-27-68755363

${ }^{b}$ Department of Chemsitry, The Hongkong University of Science and Technology, Kowloon, Hongkong, China

$\dagger$ Electronic supplementary information (ESI) available: Experimental details including the synthesis of compounds 1, 2, 3 and 4, IR spectra, TEM images and SEM images, SEM-EDX and TEM-EDX, and NMR spectra and mass spectra. See DOI: $10.1039 / \mathrm{c} 3 \mathrm{tc} 31888 \mathrm{e}$ during storage and in usage. ${ }^{4}$ Since the precursor structure could influence the structure of the carbon materials, leading to the possibly different magnetic properties, it is badly needed to know more about the relationship between the precursors and products.

Polyhedral oligosilsesquioxanes (POSS), is a type of organic/ inorganic hybrid nanostructured molecule, which contains a $\mathrm{Si}-\mathrm{O}$ core and organic surface. Due to its special cubic cage structure, it is a useful nanometer-scale building block in a wide range of polymeric materials and nanocomposites, to improve the thermal stability, mechanical properties, dielectric properties, anti-aggregation properties, oxidation resistance and flame resistance of the materials. ${ }^{5}$ Considering that POSS molecules may hinder small metal nanoparticles aggregating into larger particles to adjust the size and the structure of the resultant nanomaterials, ${ }^{6}$ and can be converted into $\mathrm{SiO}_{2}$ after pyrolysis to prevent the metal nanoparticles from being oxidized more effectively, ${ }^{7}$ we attempted to introduce POSS groups into organometallic precursors, with the aim of obtaining new carbon/metal nanocomposites with controllable structure and improved stability through the solid-state pyrolysis method. Interestingly, so far, no related work has been reported concerning the POSS-containing organometallic precursors.

Therefore, in this work, to obtain new cobalt nanoparticlesbased magnetic materials, two representative organometallic precursors PM1 and PM2 containing POSS and cobalt moieties were successfully synthesized, in which PM1 contained one $\left[\mathrm{Co}_{2}(\mathrm{CO})_{6}\right]$ unit, while PM2 contained two. The different 
concentrations of $\left[\mathrm{Co}_{2}(\mathrm{CO})_{6}\right]$ could regulate the metal-aromatic carbon ratio, thereby controlling the morphology of the resultant carbon/metal nanocomposites upon solid-state pyrolysis. For comparison, their analogues, M1 and M2, without POSS moieties, were also prepared. After pyrolysis, the obtained carbon/ metal nanocomposites demonstrated good magnetic properties, with Ms values up to 33.4 emu $\mathrm{g}^{-1}$. Interestingly, their morphology could be well controlled as nanospheres or nanotubes, and their size could be adjusted by the introduction of the POSS moieties, once again confirming the power of the concept of precursor-controlled pyrolysis towards defined carbon materials. Herein, we would like to present the syntheses, characterization, morphology, and properties in detail.

\section{Results and discussion}

\section{Synthesis and structural characterization}

Organometallic precursors M1, M2, PM1 and PM2 were all prepared by the reaction between an alkynyl-functionalized organic framework and a large excess of $\left[\mathrm{Co}_{2}(\mathrm{CO})_{8}\right]$ (Scheme 1), with satisfactory yields (higher than $60 \%$ ). Scheme S1† illustrates the synthetic routes of compounds 1, 2, 3 and 4, through the efficient esterification reaction, compounds 3 and 4 containing POSS moieties were prepared with high yields. It should be pointed out that the whole syntheses were straight forward with relatively high yields, and the purification procedure was very simple with high efficiency. This would make the products relatively cheap, once they have been commercialized.

All the final products and intermediates were well characterized by spectroscopic methods, including nuclear magnetic resonance (NMR), mass spectroscopy, elemental analyses (EA) and Fourier transform infrared (FTIR) spectra, which confirmed

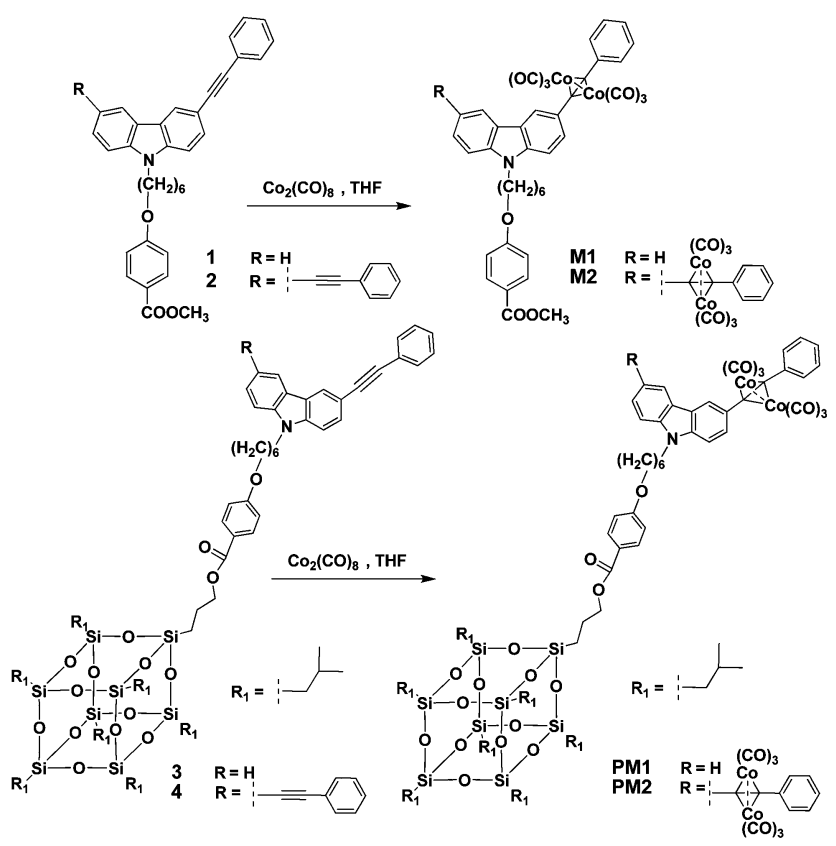

Scheme 1 Synthetic pathway of the compounds M1, M2, PM1 and PM2. their explicit molecular structures (Fig. S9-S38†). After incorporation with the $\left[\mathrm{Co}_{2}(\mathrm{CO})_{6}\right]$ unit, the ${ }^{13} \mathrm{C}$ NMR spectra (Fig. S28, S31, S34 and S37†) demonstrated obvious signal shifts for the carbons of the alkynyl groups, and a single signal assigned to the carbonyl carbon of $\left[\mathrm{CCCo}_{2}(\mathrm{CO})_{6}\right]$ appeared at about $199 \mathrm{ppm}$. Fig. 1 shows the IR spectra of 2, M2 and PM2. The stretching vibration of the alkynyl groups of 2 was observed at $2208 \mathrm{~cm}^{-1}$, which completely disappeared in $\mathbf{M} 2$ and PM2. However, in the spectra of M2 and PM2, three strong absorption bands appeared in the range of 2019 to $2090 \mathrm{~cm}^{-1}$, which were the typical absorptions of $\left[\mathrm{CCCo}_{2}(\mathrm{CO})_{6}\right]$, confirming that $\left[\mathrm{Co}_{2}(\mathrm{CO})_{8}\right]$ has been completely reacted with alkynyl groups. The successful incorporation of the POSS cage could also be confirmed through the IR spectra: in comparison with those of 2 and M2. In the spectrum of PM2, a broad absorption band appeared at 1114 $\mathrm{cm}^{-1}$, corresponding to the stretching $\mathrm{Si}-\mathrm{O}-\mathrm{Si}$ bonds of the POSS cage. The IR spectra of 1, M1 and PM1 is given in Fig. S1, $\dagger$ and similar results were obtained. The MALDI-TOF mass spectra further proved the explicit molecular structures of the organometallic precursors. Taking M1 as an example, a peak was observed at $m / z 760.9$, which should be assigned to a parent ion with the loss of one CO group (Fig. S29†).

\section{Thermal properties}

The work from the group of Müllen and co-workers has already proven that the pyrolysis program, including heating rate, temperature, and holding time, has a significant influence on the structure of the resultant nanocomposites. Generally, the precursors were first heated to the decomposition temperature of the Co-carbonyl groups and held at this temperature for several hours, and then heated to a higher temperature and held there for several more hours. Although in our case, PM1 and PM2 contained the POSS moieties, the pyrolysis process should be similar to those reported in the literature. ${ }^{8}$

In order to obtain a more perfect result, the thermal properties of the organometallic precursors and their crude materials were investigated by thermogravimetric (TGA) analysis

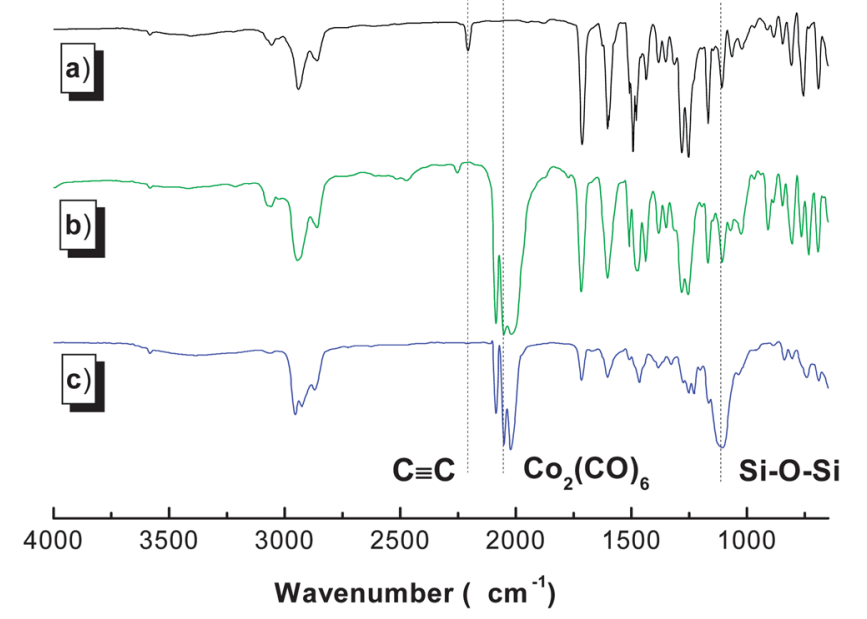

Fig. 1 IR spectra of (a) 2, (b) M2, and (c) PM2. 
(Fig. 2). The thermal-decomposition temperatures $\left(T_{\mathrm{d}}\right.$, corresponding to a $5 \%$ weight loss) of the organometallic precursors were at about $180{ }^{\circ} \mathrm{C}$. Thus, the pyrolysis program was determined as following: powders of the organometallic precursors were placed in quartz tubes sealed under a high vacuum, and were then subjected to the same heating programs. They were first heated slowly to their decomposition temperature $\left(180^{\circ} \mathrm{C}\right)$, held for $2 \mathrm{~h}$ to ensure the complete decomposition of the Co complexes, then heated to a higher temperature $\left(700^{\circ} \mathrm{C}\right)$, where the sample was held for eight hours. The experiments were also conducted at higher temperatures and for different time intervals. It was found that $700{ }^{\circ} \mathrm{C}$ was the most suitable temperature and $8 \mathrm{~h}$ was sufficient. After slowly cooling to room temperature, the obtained product was characterized by using powder X-ray diffraction, scanning electron microscopy (SEM), transmission electron microscopy (TEM), energy-dispersive spectroscopy (EDS) and a vibrating sample magnetometer.

Interestingly, in the TGA thermograms, the decomposition temperatures of the alkynyl-functionalized organic compounds 1, 2, 3 and 4 were determined to be in a range from 295 to $390{ }^{\circ} \mathrm{C}$, much higher than those of the organometallic precursors $\left(\sim 180{ }^{\circ} \mathrm{C}\right)$. This indicated that when $\left[\mathrm{CCCo}_{2}(\mathrm{CO})_{6}\right]$ decomposed to cobalt nanoparticles, the POSS cage could still keep its shape. ${ }^{9}$ Thus, to a certain extent, it was expected that the POSS cage should be able to hinder small cobalt nanoparticles aggregating into larger particles.
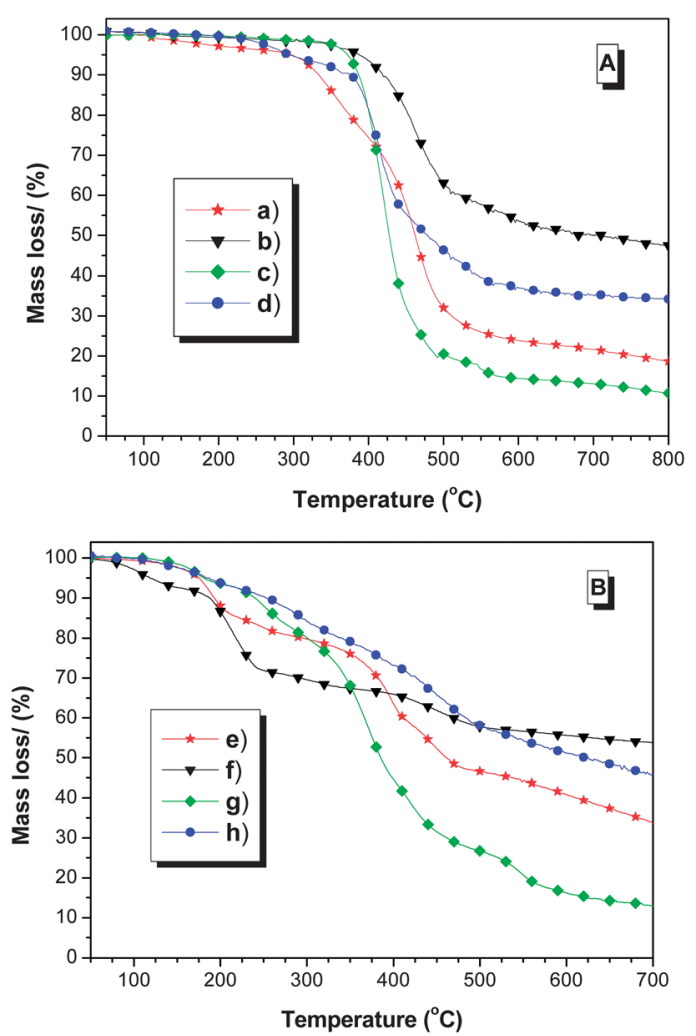

Fig. 2 TGA thermograms of (a) 1, (b) 2, (c) 3, (d) 4; (e) M1, (f) M2, (g) PM1 and (h) PM2 measured under nitrogen at a heating rate of $10^{\circ} \mathrm{C} \mathrm{min}^{-1}$.

\section{Nanosphere and nanotube formation by the pyrolysis of precursors}

As discussed above, the precursor-controlled pyrolysis process is a powerful approach to yield defined carbon materials . Also actually, the prepared organometallic complexes could be easily converted to two types of carbon/metal nanocomposites, nanospheres and nanotubes, under the same pyrolysis program with high yield and purity.

The solid-state pyrolysis (SSP) of M1 and PM1, both gave uniform nanospheres with a core-shell structure. For precursor M1, SEM and TEM analysis showed that the diameter of the formed nanospheres was mainly about $110 \mathrm{~nm}$ (Fig. 3a-d). As shown in Fig. 3c, it is easily seen that Co nanoparticles were embedded in carbonaceous materials, mainly amorphous carbon with a thickness of about $8 \mathrm{~nm}$ (Fig. 3d). SEM and TEM analysis of precursor PM1 showed that the diameter of the nanospheres mainly ranged from 8 to $20 \mathrm{~nm}$, and the metallic Co nanoparticles were encapsulated very well (Fig. 3e-h). From the high-resolution TEM image (Fig. $3 \mathrm{~h}$ and $\mathrm{S} 2 \dagger$ ), we can see that the Co NPs have a graphitic coating. The number of graphitic shells ranged from 4 to 6 , and the spacing between the layers was $3.58 \AA$, consistent with the range reported for the interplanar spacings of graphite $\left(d_{002}=3.4-3.9 \AA\right) .{ }^{10}$ Comparing between the obtained nanospheres M1 (Fig. 3a-d) and PM1 (Fig. 3e-h), we found that the introduction of POSS groups could make the nanospheres have a much smaller size with a better dispersibility.

Unlike the cases of M1 and PM1, the pyrolysis of compounds M2 and PM2 produced uniform multiwalled CNTs in high yields. Transmission electron microscopy (TEM) analysis revealed that the average inner and outer diameters of the CNTs were 36 and $80 \mathrm{~nm}$ for $\mathbf{M 2}$, respectively (Fig. $4 \mathrm{~b}$ and c).

The tubes are well graphitized, made up of 30-40 layers, with a $d_{002}$ of $3.45 \AA$ (Fig. $4 \mathrm{~d}$ ). The Co particles having a diameter of 40-100 nm, were located mainly at the tip of the CNTs and wrapped in orderly graphene layers (Fig. 4c and S3c $\dagger$ ), or encapsulated by well graphitized carbon nanospheres (Fig. S3b $\dagger$ ). As for the precursor PM2, the obtained CNTs have a uniform size with an inner diameter of about $20 \mathrm{~nm}$ and an outer diameter of about $40 \mathrm{~nm}$ (Fig. $4 \mathrm{e}-\mathrm{h}$ ), almost half of the size of the CNTs obtained from M2, the wall of the CNTs here was composed of oblique graphene fragments (always comprised of 20 graphene layers), and the interlayer distance was $3.57 \AA$ (Fig. 4h). Also, there were many clean CNTs without the presence of Co particles (Fig. S3e $\dagger$ ). Very different from the case of M2, there were many small Co nanoparticles with a diameter of about $10 \mathrm{~nm}$ in the CNTs (Fig. 4g), and these Co nanoparticles also had a good graphitic coating (Fig. S3f $\dagger$ ). The high-resolution TEM image showed that the well-structured graphite layers were covered with a layer of amorphous materials (Fig. $4 \mathrm{~d}$ and $\mathrm{h}$ ).

Meanwhile, an abnormal phenomenon was observed in the case of precursor M2: there was a small shorter CNT with a length of $500 \mathrm{~nm}$ in a larger CNT (Fig. S4a-c $\dagger$ ). Although the formation of this structure was not fully understood, it might stimulate the interest of other scientists to research the internal 

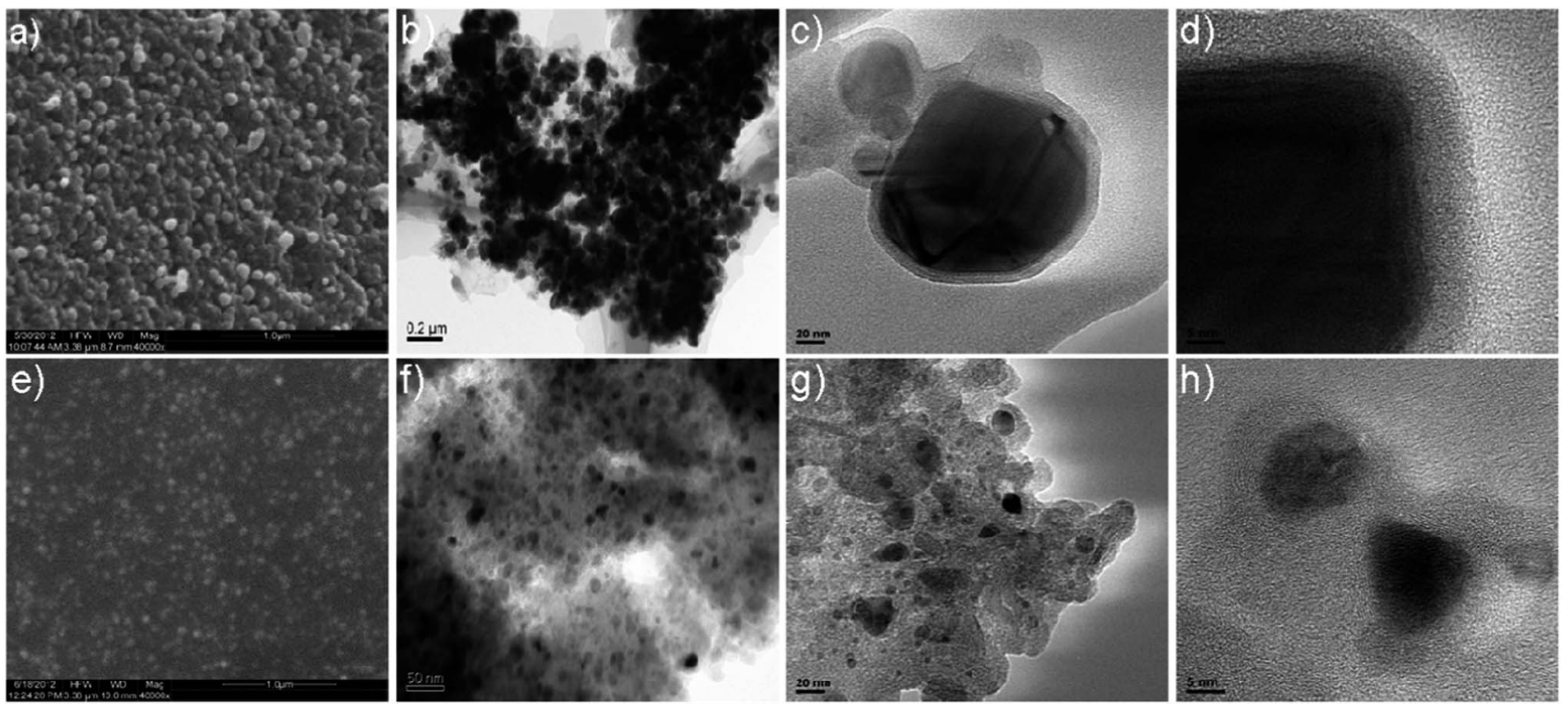

Fig. 3 SEM ( $a$ and e) and TEM (b, c, d, f, g and h) images of the materials obtained through thermolysis of compounds M1 and PM1. (a, b, c and d) for precursor M1, (e, f, $g$ and $h$ ) for precursor PM1. TEM images at high magnifications ( $d$ and $h$ ).

mechanism. Also, some bamboo-shaped CNTs (Fig. S4d $\dagger$ ) were formed, possibly due to the presence of nitrogen atoms, which have been previously observed in nitrogen-doped CNTs. ${ }^{11}$

The results as described above, confirmed that the structure and morphology of the nanomaterials could be controlled by regulating the number of the $\left[\mathrm{Co}_{2}(\mathrm{CO})_{6}\right]$ moieties and the introduction of the POSS moieties. When there were two $\left[\mathrm{Co}_{2}(\mathrm{CO})_{6}\right]$ moieties, such as compounds $\mathbf{M} 2$ and PM2, uniform nanotubes with graphitic wall structures could be yielded, however, the decrease of the number of the $\left[\mathrm{Co}_{2}(\mathrm{CO})_{6}\right]$ moieties from two to one as M1 and PM1, generated nanospheres with a core-shell structure. The main reason should be the metal loading concentrations of the precursors, which changed the ratio between the metal and aromatic carbon atoms. With a low metal loading concentration, the metal catalyst was not enough to catalyze the formation of the CNTs. ${ }^{12}$ Just by adjusting the concentration of the $\left[\mathrm{Co}_{2}(\mathrm{CO})_{6}\right]$ moieties to a higher level, beautiful nanotubes could be obtained. As to precursor PM2, the introduction of POSS groups also imported a large number of alkyl chains to reduce the ratio between the metal and carbon atoms, but considering the six-membered-ring-based growth model for the growth of CNTs with benzene precursor, ${ }^{13}$ we
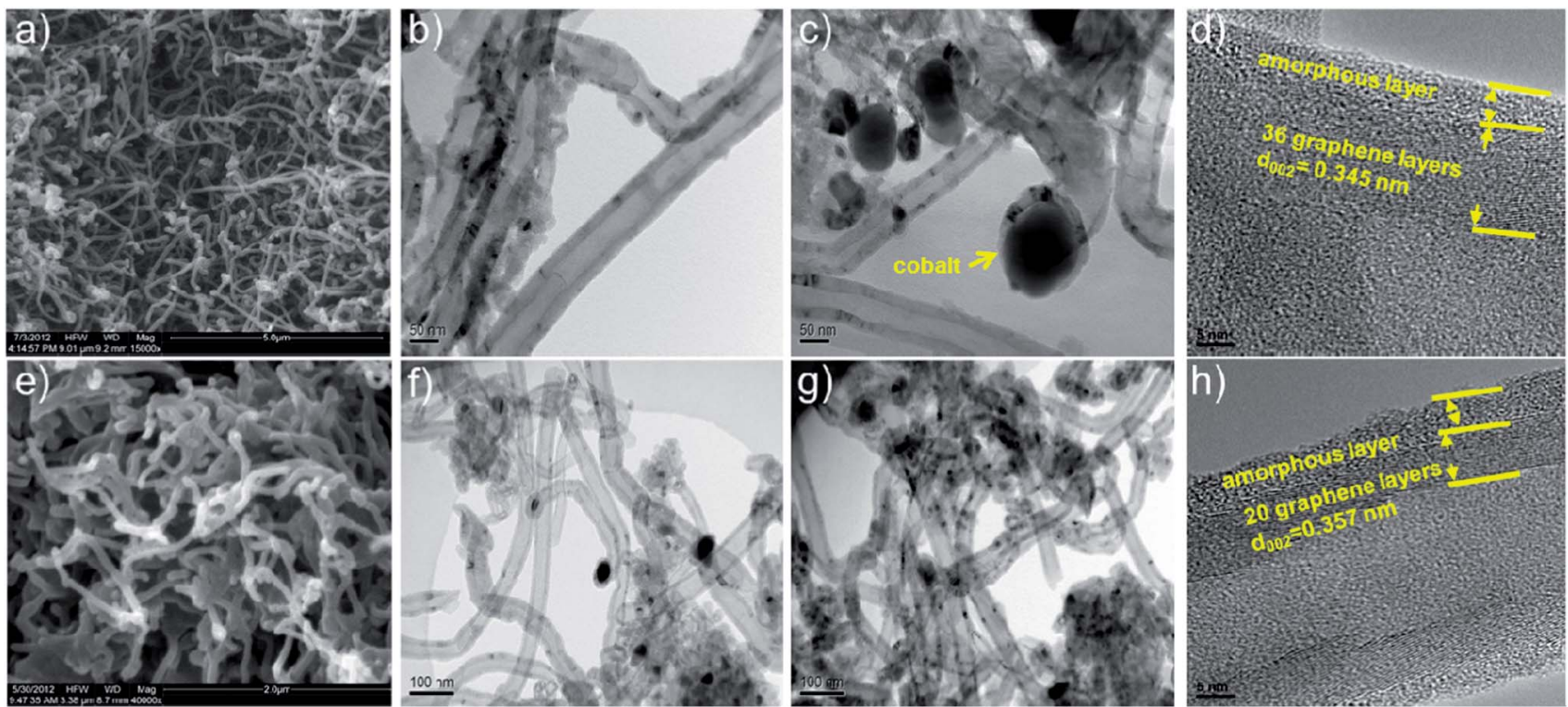

Fig. $4 \operatorname{SEM}(a, e)$ and TEM ( $b, c, d, f, g$ and $h)$ images of the materials obtained through the thermolysis of compounds M2 and PM2. (a, b, $c$ and d) for precursor M2, (e, f, g and h) for precursor PM2. TEM images at high magnifications ( $d$ and $h$ ). 
thought that aromatic carbon atoms have some advantages in the formation of CNTs than the alkyl ones in our system. So we used the ratio between the metal and aromatic carbon atoms to evaluate the concentration of the cobalt, and in this case, PM2 has a higher ratio between the metal and aromatic carbon atoms, so it still produced beautiful nanotubes.

On the other hand, the presence of the POSS group can adjust the size of the resultant nanomaterials efficiently, in comparison with those without the POSS moieties, the POSScontaining organometallic precursors produced nanomaterials with a much smaller size. It was proposed that the POSS group (possibly the presence of the silicon-oxygen cage) efficiently hampered the movement of cobalt nanoparticles, thus preventing small cobalt NPs aggregating into larger particles.

\section{Composition of the nanocomposites}

In order to gain more insight into the crystal phase and chemical compositions of the obtained nanocomposites, we investigated the organometallic precursors and nanocomposites by powder $\mathrm{X}$-ray diffraction (XRD) and energy-dispersion X-ray (EDX). To differentiate between the nanocomposites and their precursors, the nanocomposites obtained by the SSP of M1, M2, PM1 and PM2 were named as M1-S, M2-S, PM1-S and PM2-S respectively.

Fig. 5 shows the XRD patterns of the organometallic precursors before pyrolysis. All the spectra showed a broad diffraction peak near $20^{\circ}$ due to the amorphous silica matrix. The diffraction peaks of PM1 and PM2, which appeared at $2 \theta=$ $8.3^{\circ}(1.07 \mathrm{~nm})$ were associated with the hexagonal crystalline structure of the POSS cage. ${ }^{14}$ Fig. 6 shows the XRD patterns of the nanocomposites, which exhibited Bragg reflections at the $2 \theta$ angles of $44.3,51.7$ and $76.2^{\circ}$. These reflection peaks can be identified to the (111), (200) and (220) planes of Co with a face centered cubic (fcc) structure. ${ }^{15}$ However, there were no obvious diffraction peaks observed at about $26^{\circ}$, which was the typical signal for the graphite structure. There might be two possible reasons: one was that the broad diffraction peak of the amorphous silica matrix hid the graphitic peak and influenced the

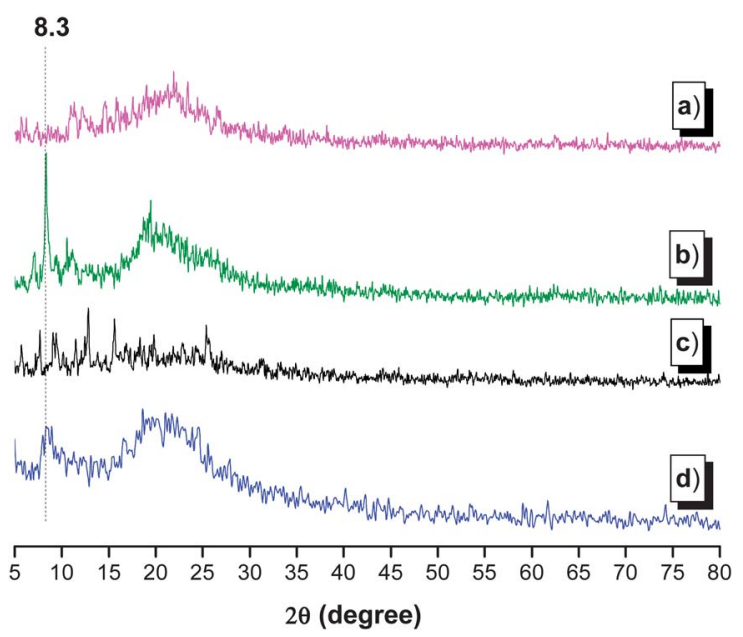

Fig. 5 XRD diffractograms of (a) M1, (b) PM1, (c) M2 and (d) PM2 before pyrolysis.

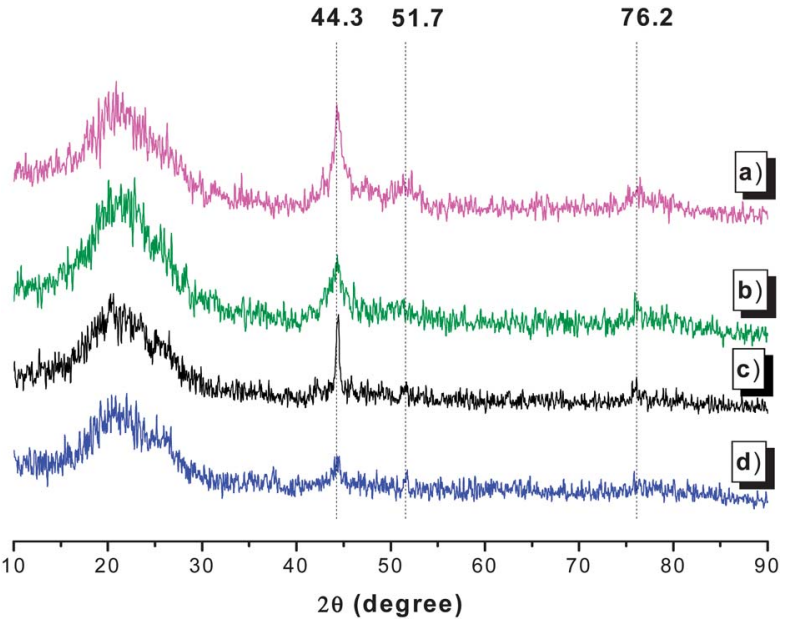

Fig. 6 XRD diffractograms of (a) M1, (b) PM1, (c) M2 and (d) PM2 after pyrolysis.

observation, another one was that there were some metallic cobalt or other impurities covered on the graphene layers of the as-synthesized samples (see the HRTEM images). ${ }^{16}$ As the content of Co particles increased, the intensity of the diffraction peaks became narrower and sharper, indicating an improvement in crystallinity and enlargement of the cobalt nanocrystallite size. The peaks for the fcc-Co in M2-S were sharper than the other nanomaterials, revealing that the crystallites were more perfect and larger in size ${ }^{17}$ However, the intensity of diffraction peaks of PM2-S, with the higher concentration of metal contents than that of PM1-S, were the most inconspicuous, possibly due to the smallest size of the Co nanoparticles (see Fig. 4g).

SEM-EDX and TEM-EDX were used to analyse the chemical compositions and element distribution of the obtained nanocomposites. From the SEM-EDX (Table 1 and Fig. S5 $\dagger$ ) measurements, the cobalt contents in the bulk of M1-S, M2-S, PM1-S and PM2-S were tested to be 22.63, 14.18, 27.23 and $19.08 \%$, respectively, and their carbon contents were 77.37 , 35.11 , 62.76 and $39.98 \%$, respectively. Compared to the compositions of organometallic precursors (Table S1†), the cobalt contents of the obtained nanocomposites all increased. For M1-S, only carbon and cobalt elements could be easily detected, thus, the oxygen atoms that existed in compound M1 were transformed into some oxygen-containing gas compounds. However, a small amount of silicon and oxygen

Table 1 Compositions of M1-S, PM1-S, M2-S, and PM2-S, estimated by SEM-EDX analyses

\begin{tabular}{lllll}
\hline Sample & C (\%) & Co (\%) & Si (\%) & O (\%) \\
\hline M1-S & $77.37(61.00)^{a}$ & $22.63(14.97)$ & $0.00(0.00)$ & $0.00(18.28)$ \\
PM1-S & $35.11(51.55)$ & $14.18(7.23)$ & $21.76(13.78)$ & $28.95(20.60)$ \\
M2-S & $62.76(55.26)$ & $27.34(20.09)$ & $2.98(0.00)$ & $6.92(20.45)$ \\
PM2-S & $39.98(50.02)$ & $19.08(11.69)$ & $15.50(11.14)$ & $25.44(21.42)$
\end{tabular}

${ }^{a}$ The numbers in parentheses represent the content of the element in the corresponding organometallic precursors. 
was found in M2-S, possibly due to some $\mathrm{SiO}_{2}$ that came from the quartz tubes used in the pyrolysis experiments. PM1-S and PM2-S, derived from the POSS containing precursors, possessed a high contents of silicon and oxygen atoms. At the same time, the carbon contents of M1-S and M2-S increased, but decreased in PM1-S and PM2-S. All of this indicated that the siliconoxygen cage of the POSS group was converted into $\mathrm{SiO}_{x}$ after pyrolysis.

The HRTEM images have already indicated the core-shell architecture of M1-S and PM1-S. TEM-EDX was used to analyse the chemical compositions of the core-shell architecture and found the existing place of $\mathrm{SiO}_{x}$ in PM1-S and PM2-S. When the electron beam passed through the center and the shell of M1-S (Fig. S6a and $\mathrm{b} \dagger$ ), Co and $\mathrm{C}$ were the main elements detected. This indicated that the core-shell nanospheres had a Co@C architecture. When the electron beam passed through the center of PM1-S, Co atoms together with fewer C atoms in the core showed up in Fig. S6c. $\uparrow$ When the electron beam passed through the shell, all the elements of Co, C, Si and O were detected (Fig. S6d $\dagger$ ). The presence of Si and $\mathrm{O}$ in the shell, and the change of the relative concentrations of each element between the center and the shell, indicated that the core-shell nanospheres had a Co@C-SiO $x$ architecture. Also, the TEM-EDS analysis results in Fig. $\mathrm{S} 7 \mathrm{a}-\mathrm{d} \dagger$ clearly demonstrate the chemical compositions and element distribution of M2-S and PM2-S. From the HRTEM, SEM-EDX and TEM-EDX analysis results, we could make the conclusion that the silicon-oxygen cage of the POSS group in the precursors was converted into $\mathrm{SiO}_{x}$ upon pyrolysis, and the formed $\mathrm{SiO}_{x}$ was covered on the surface of the graphitic wall. This architecture would be beneficial in preventing the nano-cobalt from being oxidized more effectively.

\section{Magnetism of the nanocomposites}

We studied the magnetic properties of the nanomaterials, all the CNPs are magnetizable and can be readily attracted to a magnet at room temperature. To quantitatively investigate their magnetic behavior, the nanomaterials were characterized by using a vibrating sample magnetometer. Fig. 7 shows the magnetization curves of the magnetic nanoparticles, all the obtained nanomaterials exhibit soft-magnetic behavior with

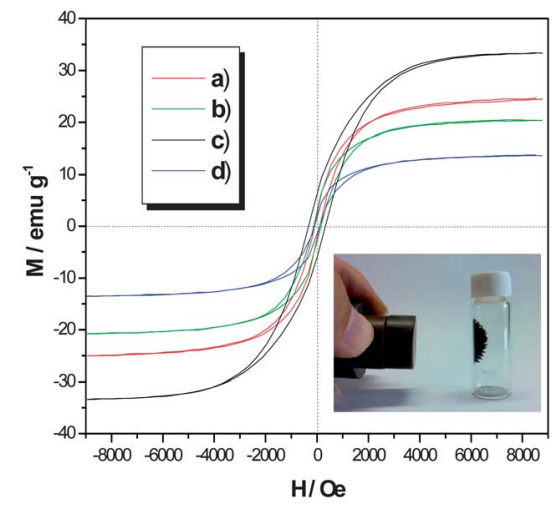

Fig. 7 Plots of magnetization $(M)$ versus applied magnetic field $(H)$ at $300 \mathrm{~K}$ for (a) M1-S, (b) PM1-S, (c) M2-S, and (d) PM2-S.
Table 2 Magnetization data for various samples measured at $300 \mathrm{~K}$

\begin{tabular}{llllc}
\hline Sample & $M_{\mathrm{S}}\left(\mathrm{emu} \mathrm{g}^{-1}\right)$ & $M_{\mathrm{r}}\left(\mathrm{emu} \mathrm{g}^{-1}\right)$ & $M_{\mathrm{r}} / M_{\mathrm{S}}$ & $\mathrm{Hc}(\mathrm{Oe})$ \\
\hline M1-S & 24.4 & 2.21 & 0.09 & 88 \\
PM1-S & 20.4 & 2.83 & 0.14 & 126 \\
M2-S & 33.4 & 6.02 & 0.18 & 327 \\
PM2-S & 13.8 & 1.73 & 0.13 & 99
\end{tabular}

high magnetizabilities. The magnetization data is shown in Table 2. The saturation magnetization (Ms) ranged from 13.8 to 33.4 emu g $^{-1}$, and the order of the Ms was M2-S > M1-S > PM1-S, consistent with their metallic contents. However, the saturation magnetization of PM2-S was lower than that of PM1-S, possibly due to its poor crystallinity and small size (see XRD diffractogram Fig. 6). ${ }^{18}$ Overall, considering the relatively lower concentration of their metal contents, the obtained nanomaterials showed good magnetic properties, ${ }^{19}$ possibly as a result of their high oxidation resistance. The SEM measurements of M2-S and PM2-S were carried out without coating with gold metal (Fig. S8 $\dagger$ ). The clear images of the SEM photographs indicated that the nanomaterials are electrically highly conductive, possibly due to their conductive graphite carbon and metallic cobalt. ${ }^{20}$

\section{Conclusions}

In summary, four organometallic precursors containing cobalt moieties were synthesized successfully. To the best of our knowledge, this is the first utilization of solid-state pyrolysis (SSP) of POSS group-containing organometallic precursors to generate nanocomposites. By simple structural modification, uniform nanotubes and nanospheres could be controllably prepared efficiently with high selectivity, and their morphology and size could be controlled by regulating the number of $\left[\mathrm{Co}_{2}(\mathrm{CO})_{6}\right]$ moieties and introducing the POSS group. The obtained nanomaterials all show good magnetic properties. Coupled with their high oxidation resistance and good stability, they could be promising candidates in practical magnetic applications. Thus, the preliminary results confirmed the power of the method of the solid-state pyrolysis of organometallic precursors, and also provided some useful information for the further development of POSS containing materials in the research field of nanomaterials.

\section{Experimental}

\section{Materials and instrumentation}

Tetrahydrofuran (THF) was dried over and distilled from $\mathrm{K}-\mathrm{Na}$ alloy under an atmosphere of dry nitrogen. Triethylamine $\left(\mathrm{Et}_{3} \mathrm{~N}\right)$ was distilled under normal pressure and kept over potassium hydroxide. Dichloromethane (DCM) was dried over and distilled from $\mathrm{CaH}_{2}$. PSS-(3-hydroxypropyl)-heptaisobutyl substituted (POSS) was purchased from Sigma-Aldrich, octacarbonyldicobalt was purchased from Alfa Aesar. All other reagents were used as received without further purification. ${ }^{1} \mathrm{H}$ and ${ }^{13} \mathrm{C}$ NMR 
spectroscopy studies were conducted with a Varian Mercury 300 spectrometer using tetramethylsilane (TMS; $\delta=0 \mathrm{ppm}$ ) as an internal standard. EI-MS spectra were recorded with a Finnigan PRACE mass spectrometer. MALDI-TOF mass spectra were measured on a Voyager-DE-STR MALDI-TOF mass spectrometer or a GCT premier CAB048 mass spectrometer using a $337 \mathrm{~nm}$ nitrogen laser and CHCA or DCTB as a matrix. The Fourier transform infrared (FTIR) spectra were recorded on a PerkinElmer-2 spectrometer in the region of $4000-400 \mathrm{~cm}^{-1}$. Thermal analysis was performed on a Netzsch STA 449C thermal analyzer at a heating rate of $10{ }^{\circ} \mathrm{C} \mathrm{min}{ }^{-1}$ in nitrogen at a flow rate of $20 \mathrm{~cm}^{3} \mathrm{~min}^{-1}$ for thermogravimetric analysis (TGA). Elemental analyses were performed by a CARLOERBA1106 by a micro-elemental analyzer. TEM was performed on a JEM-2010HT or JEM-2010FEF microscope at an accelerating voltage of $200 \mathrm{kV}$. The TEM samples were prepared by drying a droplet of the suspension on a TEM copper grid with a carbon film. SEM was performed on a QUANTA scanning electron microscope. Energy-dispersive X-ray spectroscopy (EDS) was taken on the SEM or that attached to the TEM. The XRD analyses were performed on a Bruker D8 Advanced X-ray diffractometer with $\mathrm{Cu}_{\mathrm{K} \alpha}$ radiation $(\lambda=1.5418 \AA)$. Magnetization curves were recorded on a Lake Shore 7037/9509-P vibrating sample magnetometer at room temperature.

\section{General procedure for the synthesis of compounds M1, M2, PM1 and PM2}

Typically, $\left[\mathrm{Co}_{2}(\mathrm{CO})_{8}\right]$ (5.00 equiv) and compound 1 or 2 or 3 or 4 (1.00 equiv) were dissolved in THF under an argon atmosphere. The mixture was stirred overnight at room temperature and the solvent was removed under vacuum. The residue was purified by using column chromatography on neutral $\mathrm{Al}_{2} \mathrm{O}_{3}$.

Compound M1: compound $1(0.20 \mathrm{~g}, 0.4 \mathrm{mmol})$. Purified by column chromatography on neutral $\mathrm{Al}_{2} \mathrm{O}_{3}$ using $\mathrm{CH}_{2} \mathrm{Cl}_{2}$ /petroleum ether (1/4) as eluent to afford a brown solid (0.21 g, 67\%). ${ }^{1} \mathrm{H} \mathrm{NMR}\left(300 \mathrm{MHz}, \mathrm{CDCl}_{3}\right) \delta(\mathrm{ppm}): 8.35$ (s, 1H, ArH), 8.08 (d, $J=$ $7.5 \mathrm{~Hz}, 1 \mathrm{H}, \mathrm{ArH}), 7.96(\mathrm{~d}, J=8.1 \mathrm{~Hz}, 2 \mathrm{H}, \mathrm{ArH}), 7.72(\mathrm{~m}, 3 \mathrm{H}, \mathrm{ArH})$, $7.41(\mathrm{~m}, 7 \mathrm{H}, \mathrm{ArH}), 6.87$ (d, $J=8.4 \mathrm{~Hz}, 2 \mathrm{H}, \mathrm{ArH}), 4.33$ (br, 2H, -O$\mathrm{CH}_{2}{ }^{-}$), 3.98 (br, 2H, -N- $\mathrm{CH}_{2}-$ ), 3.88 (s, 3H, $-\mathrm{O}-\mathrm{CH}_{3}$ ), 1.95 (br, $2 \mathrm{H},-\mathrm{N}-\mathrm{CH}_{2} \mathrm{CH}_{2}-$ ), 1.79 (br, $\left.2 \mathrm{H},-\mathrm{O}-\mathrm{CH}_{2} \mathrm{CH}_{2}-\right), 1.55(\mathrm{~m}, 4 \mathrm{H}) .{ }^{13} \mathrm{C}$ NMR (75 MHz, $\left.\mathrm{CDCl}_{3}\right) \delta(\mathrm{ppm}): 199.8,167.2,163.1,140.4,131.8$, $129.5,129.2$, 128.0, 126.5, 122.7, 121.3, 120.9, 119.6, 114.3, 109.2, 92.5, 68.1, 52.1, 43.4, 29.2, 27.3, 26.2. MS (MALDI-TOF), $m / z:[\mathrm{M}-\mathrm{CO}]^{+}$760.9, $[\mathrm{M}-2 \mathrm{CO}]^{+}$732.8. Anal. calcd for $\mathrm{C}_{40} \mathrm{H}_{31} \mathrm{Co}_{2} \mathrm{NO}_{9}$ : C 61.00, $\mathrm{H} 3.97, \mathrm{~N} 1.78$; found: $\mathrm{C} \mathrm{60.88,} \mathrm{H} 4.01$, $\mathrm{N}$ 1.87. FTIR (thin film), $\nu\left(\mathrm{cm}^{-1}\right): 2019,2051,2086\left(\mathrm{Co}_{2}(\mathrm{CO})_{6}\right)$.

Compound M2: compound $2(0.24 \mathrm{~g}, 0.4 \mathrm{mmol})$. Purified by column chromatography on neutral $\mathrm{Al}_{2} \mathrm{O}_{3}$ using $\mathrm{CH}_{2} \mathrm{Cl}_{2} / \mathrm{PE}(1 / 5)$ as eluent to afford a brown solid (0.37 g, 79\%). ${ }^{1} \mathrm{H}$ NMR $(300$ $\left.\mathrm{MHz} \mathrm{CDCl}_{3}\right) \delta(\mathrm{ppm}): 8.34(\mathrm{~s}, 2 \mathrm{H}, \mathrm{ArH}), 7.97(\mathrm{~d}, J=8.7 \mathrm{~Hz}, 2 \mathrm{H}$, ArH), 7.76 (d, $J=9.0 \mathrm{~Hz}, 2 \mathrm{H}, \mathrm{ArH}), 7.69$ (d, $J=5.7 \mathrm{~Hz}, 4 \mathrm{H}, \operatorname{ArH})$, $7.40(\mathrm{~m}, 8 \mathrm{H}, \mathrm{ArH}), 6.88$ (d, $J=9.0 \mathrm{~Hz}, 2 \mathrm{H}, \mathrm{ArH}), 4.34(\mathrm{t}, J=7.5$ $\left.\mathrm{Hz}, 2 \mathrm{H},-\mathrm{O}-\mathrm{CH}_{2}-\right), 3.99\left(\mathrm{t}, J=6.3 \mathrm{~Hz}, 2 \mathrm{H},-\mathrm{N}-\mathrm{CH}_{2}-\right), 3.88(\mathrm{~s}, 3 \mathrm{H}$, $-\mathrm{O}-\mathrm{CH}_{3}$ ), 1.97 (br, 2H, $-\mathrm{N}-\mathrm{CH}_{2} \mathrm{CH}_{2}-$ ), 1.81 (br, $2 \mathrm{H},-\mathrm{O}-\mathrm{CH}_{2}-$ $\mathrm{CH}_{2}-$ ) 1.58 (m, 4H). ${ }^{13} \mathrm{C}$ NMR (75 MHz, $\mathrm{CDCl}_{3}$ ) $\delta(\mathrm{ppm}):$ 199.8, 167.2 , 163.0, 140.9, 139.0, 131.9, 129.5, 129.2, 128.3, 128.0,
123.2, 122.7, 121.3, 114.3, 109.7, 93.6, 92.4, 68.1, 52.1, 43.7, 29.3, 27.4, 26.2. MS (MALDI-TOF), $m / z$ : $[\mathrm{M}-2 \mathrm{CO}-3 \mathrm{H}]^{+}$1113.5. Anal. calcd for $\mathrm{C}_{54} \mathrm{H}_{35} \mathrm{Co}_{4} \mathrm{NO}_{15}$ : C 55.26, $\mathrm{H} \mathrm{3.01,} \mathrm{N} \mathrm{1.19}$; found: $\mathrm{C}$ 55.16, H 3.29, N 1.31. FTIR (thin film), $\nu\left(\mathrm{cm}^{-1}\right): 2021,2052$, $2086\left(\mathrm{Co}_{2}(\mathrm{CO})_{6}\right)$.

Compound PM1: compound 3 (0.11 g, $0.4 \mathrm{mmol})$. Purified by column chromatography on neutral $\mathrm{Al}_{2} \mathrm{O}_{3}$ using $\mathrm{CH}_{2} \mathrm{Cl}_{2}$ /petroleum ether (1/4) as eluent to afford a brown solid $(0.09 \mathrm{~g}, 65 \%)$. ${ }^{1} \mathrm{H}$ NMR (300 MHz, $\mathrm{CDCl}_{3}$ ) $\delta$ (ppm): 8.35 (s, 1H, ArH), 8.08 (br, 1H, ArH), 7.96 (br, 2H, ArH), 7.72 (br, 3H, ArH), 7.40 (br, 7H, ArH), 6.88 (br, 2H, ArH), 4.33 (br, 2H, $-\mathrm{O}-\mathrm{CH}_{2}-$ ), 4.24 (br, $2 \mathrm{H}$, $\left.\mathrm{Si}\left(\mathrm{CH}_{2}\right)_{2} \mathrm{CH}_{2} \mathrm{O}^{-}\right), 3.98$ (br, 2H, $\left.-\mathrm{N}-\mathrm{CH}_{2}-\right), 1.85$ (m, 13H), 1.53 (br, $4 \mathrm{H}), 0.95$ (br, 42H,- $\left.\mathrm{CH}_{3}\right), 0.72\left(\mathrm{br}, 2 \mathrm{H}, \mathrm{Si}-\mathrm{CH}_{2}\left(\mathrm{CH}_{2}\right)_{2}{ }^{-}\right), 0.60$ $\left(\mathrm{d}, J=6.3,14 \mathrm{H}, \mathrm{Si}-\mathrm{CH}_{2} \mathrm{CH}\left(\mathrm{CH}_{3}\right)_{2}\right) .{ }^{13} \mathrm{C} \mathrm{NMR}\left(75 \mathrm{MHz}, \mathrm{CDCl}_{3}\right) \delta$ (ppm): 199.9, 166.6, 163.0, 141.3, 140.4, 139.2, 131.8, 129.3, 128.4, 128.0, 126.5, 123.2, 122.8, 121.0, 119.7, 114.3, 109.2, 94.4, $68.2,66.9,43.5,29.3,27.4,25.9,24.1,22.8,8.8$. MS (MALDITOF), $m / z:[\mathrm{M}-5 \mathrm{CO}]^{+}$1487.0, $[\mathrm{M}-6 \mathrm{CO}]^{+}$1462.4, [M - 6CO$\mathrm{Co}]^{+}$1403.5, [M - 6CO-2Co $]^{+}$1344.6. FTIR (thin film), $\nu\left(\mathrm{cm}^{-1}\right)$ : 2024, 2051, $2086\left(\mathrm{Co}_{2}(\mathrm{CO})_{6}\right) ; 1116$ (Si-O-Si).

Compound PM2: Compound 4 (0.09 g, $0.06 \mathrm{mmol})$. Purified by column chromatography on neutral $\mathrm{Al}_{2} \mathrm{O}_{3}$ using $\mathrm{CH}_{2} \mathrm{Cl}_{2}$ / petroleum ether $(1 / 5)$ as eluent to afford a brown solid $(0.08 \mathrm{~g}$, $62 \%) .{ }^{1} \mathrm{H}$ NMR $\left(300 \mathrm{MHz}, \mathrm{CDCl}_{3}\right.$ ) $\delta(\mathrm{ppm}): 8.33$ (s, 2H, ArH), 7.97 $(\mathrm{d}, J=9.0 \mathrm{~Hz}, 2 \mathrm{H}, \mathrm{ArH}), 7.76(\mathrm{~d}, J=8.7 \mathrm{~Hz}, 2 \mathrm{H}, \mathrm{ArH}), 7.69(\mathrm{~d}, J=$ $6.3 \mathrm{~Hz}, 4 \mathrm{H}, \mathrm{ArH}), 7.40$ (m, 8H, ArH), 6.887 (d, $J=9.0 \mathrm{~Hz}, 2 \mathrm{H}$, $\mathrm{ArH}), 4.34$ (br, 2H, $\left.-\mathrm{O}-\mathrm{CH}_{2}-\right), 4.24\left(\mathrm{t}, J=6.4 \mathrm{~Hz}, 2 \mathrm{H}, \mathrm{Si}\left(\mathrm{CH}_{2}\right)_{2}{ }^{-}\right.$ $\left.\mathrm{CH}_{2} \mathrm{O}-\right), 4.00$ (t, $\left.J=6.0 \mathrm{~Hz}, 2 \mathrm{H},-\mathrm{N}-\mathrm{CH}_{2}-\right), 1.97(\mathrm{br}, 2 \mathrm{H}), 1.87(\mathrm{~m}$, $11 \mathrm{H}), 1.54$ (br, 4H), 0.95 (d, $\left.J=6.6,42 \mathrm{H},-\mathrm{CH}_{3}\right), 0.72(\mathrm{t}, J=8.2$ $\left.\mathrm{Hz}, 2 \mathrm{H}, \mathrm{Si}-\mathrm{CH}_{2}\left(\mathrm{CH}_{2}\right)_{2}\right)^{-}, 0.60\left(\mathrm{~d}, J=6.9,14 \mathrm{H}, \mathrm{Si}-\mathrm{CH}_{2} \mathrm{CH}\left(\mathrm{CH}_{3}\right)_{2}\right)$. ${ }^{13} \mathrm{C}$ NMR (75 MHz, $\mathrm{CDCl}_{3}$ ) $\delta(\mathrm{ppm}): 199.7,163.0,140.9,131.8$, 129.4, 129.2, 128.0, 121.4, 114.2, 109.7, 92.5, 68.1, 66.8, 53.2, $30.0,29.3,25.9,24.1,22.8,8.7$. MS (MALDI-TOF), $\mathrm{m} / \mathrm{z}$ : [M $3 \mathrm{CO}]^{+}$1930.3, $[\mathrm{M}-3 \mathrm{CO}-\mathrm{Co}]^{+} 1871.4,[\mathrm{M}-11 \mathrm{CO}-2 \mathrm{Co}]^{+}$1594.5, $[\mathrm{M}-12 \mathrm{CO}-2 \mathrm{Co}]^{+}$1563.5, $[\mathrm{M}-12 \mathrm{CO}-3 \mathrm{Co}]^{+} 1504.6,[\mathrm{M}-12 \mathrm{CO}-$ $4 \mathrm{Co}]^{+}$1445.7. FTIR (thin film), $\nu\left(\mathrm{cm}^{-1}\right): 2023,2051,2087$ $\left(\mathrm{Co}_{2}(\mathrm{CO})_{6}\right) ; 1112(\mathrm{Si}-\mathrm{O}-\mathrm{Si})$.

\section{Acknowledgements}

We are grateful to the National Fundamental Key Research Program (2011CB932702), the National Science Foundation of China (no. 21325416) for financial support; and the Center for Electron Microscopy of Wuhan University for the aid of the TEM test.

\section{Notes and references}

1 (a) P. I. Dosa, C. Erben, V. S. Iyer, K. P. C. Vollhardt and I. M. Wasser, J. Am. Chem. Soc., 1999, 121, 10430; (b) V. S. Iyer, K. P. C. Vollhardt and R. Wilhelm, Angew. Chem., Int. Ed., 2003, 42, 4379; (c) M. Laskoski, W. Steffen, J. G. M. Morton, M. D. Smith and U. H. F. Bunz, J. Am. Chem. Soc., 2002, 124, 13814; (d) S. Scholz, P. J. Leech, B. C. Englert, W. Sommer, M. Weck and U. H. F. Bunz, Adv. Mater., 2005, 17, 1052. 
2 (a) L. Zhi, T. Gorelik, R. Friedlein, J. Wu, U. Kolb, R. Salaneck and K. Müllen, Small, 2005, 1, 798; (b) B. El Hamaoui, L. Zhi, U. Kolb, J. Wu and K. Müllen, Adv. Mater., 2005, 17, 2957; (c) J. Wu, B. El Hamaoui, J. Li, L. Zhi, U. Kolb and K. Müllen, Small, 2005, 1, 210; (d) L. Zhi, Y. S. Hu, B. El Hamaoui, X. Wang, I. Lieberwirth, U. Kolb, J. Maier and K. Müllen, Adv. Mater., 2008, 20, 1727.

3 (a) A. H. Lu, E. L. Salabas and F. Schüth, Angew. Chem., Int. Ed., 2007, 46, 1222; (b) J. Liu, S. Z. Qiao, Q. H. Hu and G. Q. Lu, Small, 2011, 7, 425; (c) M. Y. Zhu and G. W. Diao, Nanoscale, 2011, 3, 2748; (d) L. H. Reddy, J. L. Arias, J. Nicolas and P. Couvreur, Chem. Rev., 2012, 112, 5818.

4 (a) M. A. Zalich, V. V. Baranauskas, J. S. Riffle, M. Saunders and T. G. S. Pierre, Chem. Mater., 2006, 18, 2648; (b) A. H. Lu, W. C. Li, E. L. Salabas, B. Spliethoff and F. Schueth, Chem. Mater., 2006, 18, 2086.

5 (a) D. B. Cordes, P. D. Lickiss and F. Rataboul, Chem. Rev., 2010, 110, 2081; (b) X. Su, S. Guang, H. Xu, X. Liu, S. Li, X. Wang, Y. Deng and P. Wang, Macromolecules, 2009, 42, 8969; (c) C. He, Y. Xiao, J. Huang, T. Lin, K. Y. Mya and X. Zhang, J. Am. Chem. Soc., 2004, 126, 7792; (d) X. Huang, C. Zhi, P. Jiang, D. Golberg, Y. Bando and T. Tanaka, Adv. Funct. Mater., 2013, 23, 1824; (e) B. H. Augustine, W. C. Hughes, K. J. Zimmermann, A. J. Figueiredo, X. Guo, C. C. Chusuei and J. S. Maidment, Langmuir, 2007, 23, 4346.

6 (a) R. K. Rana, X. N. Xu, Y. Yeshurun and A. Gedanken, J. Phys. Chem. B, 2002, 106, 4079; (b) C. L. Cheung, A. Kurtz, H. Park and C. M. Lieber, J.Phys. Chem. B, 2002, 106, 2429; (c) Y. Shibuta and S. Maruyama, Chem. Phys. Lett., 2003, 382, 381.

7 (a) A. Fina, D. Tabuani, F. Carniato, A. Frache, E. Boccaleri and G. Camino, Thermochim. Acta, 2006, 440, 36; (b) J. H. Moon, J. S. Seo, Y. Xu and S. Yang, J. Mater. Chem., 2009, 19, 4687.

8 B. El Hamaoui, L. Zhi, J. Wu, J. Li, N. T. Lucas, Z. Tomovic, U. Kolb and K. Müllen, Adv. Funct. Mater., 2007, 17, 1179.

9 (a) R. Hany, R. Hartmann, C. Bohlen, S. Brandenberger, J. Kawada, C. Lowe, M. Zinn, B. Witholt and R. H. Marchessault, Polymer, 2005, 46, 5025; (b) N. Amir, A. Levina and M. S. Silverstein, J. Polym. Sci., Part A: Polym. Chem., 2007, 45, 4264; (c) L. Liu, Y. Hu, L. Song, S. Nazare, S. He and R. Hull, J. Mater. Sci., 2007, 42, 4325.
10 C. H. Kiang, M. Endo, P. M. Ajayan, G. Dresselhaus and M. S. Dresselhaus, Phys. Rev. Lett., 1998, 81, 1869.

11 (a) P. Hu, K. Xiao, Y. Liu, G. Yu, X. Wang, L. Fu, G. Cui and D. Zhu, Appl. Phys. Lett., 2004, 84, 4932; (b) R. Czerw, M. Terrones, J. Charlier, X. Blase, B. Foley, R. Kamalakaran, N. Grobert, H. Terrones, D. Tekleab, P. M. Ajayan, W. Blau, M. Rühle and D. L. Carroll, Nano Lett., 2001, 1, 457; (c) I. Florea, O. Ersen, R. Arenal, D. Ihiawakrim, C. Messaoudi, K. Chizari, I. Janowska and C. Pham-Huu, J. Am. Chem. Soc., 2012, 134, 9672.

12 (a) G. Y. Xiong, Y. Suda, D. Z. Wang, J. Y. Huang and Z. F. Ren, Nanotechnology, 2005, 16, 532; (b) I. Stamatina, A. Morozana, A. Dumitrua, V. Ciupinab, G. Prodanb, J. Niewolskic and H. Figiel, Phys. E., 2007, 37, 44; (c) M. Kumar and Y. Ando, J. Nanosci. Nanotechnol., 2010, 10, 3739.

13 (a) Y. Tian, Z. Hu, Y. Yang, X. Wang, X. Chen, H. Xu, Q. Wu, W. Ji and Y. Chen, J. Am. Chem. Soc., 2004, 126, 1180; (b) Y. Tian, Z. Hu, Y. Yang, X. Chen, W. Ji and Y. Chen, Chem. Phys. Lett., 2004, 388, 259; (c) H. Feng, J. Ma and Z. Hu, J. Phys. Chem. C, 2009, 113, 16495.

14 (a) A. J. Waddon, L. Zheng, R. J. Farris and E. B. Coughlin, Nano Lett., 2002, 2, 1149; (b) A. J. Waddon and E. B. Coughlin, Chem.Mater., 2003, 15, 4555.

15 (a) S. Liu, X. Tang, L. Yin, Y. Koltypina and A. Gedanken, J. Mater. Chem., 2000, 10, 1271; (b) J. Ling, Y. Liu, G. Hao and X. Zhang, Mater. Sci. Eng., B, 2003, 100, 186.

16 (a) H. Huang, S. Yang and G. Gu, J. Phys. Chem. B, 1998, 102, 3420; (b) S. Liu, J. Zhu, Y. Mastai, I. Felner and A. Gedanken, Chem. Mater., 2000, 12, 2205.

17 G. Ennas, A. Falqui, S. Marras, C. Sangregorio and G. Marongiu, Chem. Mater., 2004, 16, 5659.

18 C. B. Pong, D. Li, V. Nandwana, N. Poudyal, Y. Ding, Z. L. Wang, H. Zeng and J. P. Liu, Adv. Mater., 2006, 18, 2984.

19 (a) S. Liu, J. Zhu, Y. Mastai, I. Felner and A. Gedanken, Chem. Mater., 2000, 12, 2205; (b) Y. Liu, J. Ling, W. Li and X. Zhang, Nanotechnology, 2004, 15, 43.

20 Q. Sun, J. W. Y. Lam, K. Xu, H. Xu, J. A. K. Cha, P. C. L. Wong, G. Wen, X. Zhang, X. Jing, F. Wang and B. Z. Tang, Chem. Mater., 2000, 12, 2617. 